\title{
EVOLUTION OF DAMAGED ARMOR LAYER PROFILE
}

\author{
Ali Farhadzadeh ${ }^{1}$, Nobuhisa Kobayashi ${ }^{1}$ and Jeffrey A. Melby ${ }^{2}$
}

\begin{abstract}
A probabilistic hydrodynamic model for the wet and dry zone on a permeable structure is developed to predict irregular wave action on the structure above the still water level. The model is based on the time-averaged continuity and momentum equations for nonlinear shallow-water waves coupled with the exponential probability distribution of the water depth. The model predicts the cross-shore variations of the mean and standard deviation of the water depth and horizontal velocity. Damage progression of a stone armor layer is predicted by modifying a formula for bed load on beaches with input from the hydrodynamic model. The damage progression model is compared with three tests by Melby and Kobayashi (1998) that lasted up to 28.5 hours. The model predicts the temporal progression of the eroded area quite well. The numerical model is very efficient and suited for a risk-based design of rubble mound structures.

Keywords: rubble-mound breakwater; damage progression, coastal structure, wave-structure interaction, armor layer
\end{abstract}

\section{INTRODUCTION}

Rubble mound structures are widely used to protect the landward area including a port or harbor against wave attack mostly because they dissipate wave energy more effectively than impermeable structures. Design of rubble mound breakwaters has always been challenging because the wave hydrodynamics near and on the structures alters during storms as the breakwater profile changes. The traditional design methods for rubble mound breakwaters treat the wave hydrodynamics and the design of the armor layer separately. The wave-structure interaction and the armor layer profile change should be considered together in the design procedure.

The advanced time-dependent hydrodynamic models for rubble mound structures try to predict the temporal and spatial variations of wave dynamics as accurately as possible. The more accurate hydrodynamic models, in general, require longer computation time. To reduce computation time considerably, Kobayashi et al. (2007) proposed a probabilistic model. The time-dependent wave variables are expressed using a probability distribution. The time-averaged governing equations are used to compute the hydrodynamic variables. The model was developed to include wave and current interaction (Farhadzadeh et al. 2007). Later, the probabilistic model was extended to the wet and dry zone in order to predict wave runup and overtopping (Kobayashi and Farhadzadeh 2008).

Kobayashi and Otta (1987) developed a time-dependent model to predict the stone movement under regular wave attack. The model utilized the equation of motion for each individual armor unit in order to estimate the stone movement. The armor layer evolution then can be estimated by predicting the movement of all the individual stone units. In practice, however, this approach has never been used probably because of its computation time.

In the present study the probabilistic model for the wet and dry zone is extended to include the permeability effects. The new model is capable of predicting the wave and flow motion above and inside the permeable armor layer in the wet and dry zone. The probabilistic model for the permeable wet and dry model coupled with the permeable wet model can predict the irregular wave transformation and the flow hydrodynamic from the offshore boundary to the landward end of a rubble mound structure. The extended model provides the hydrodynamic input to a damage progression model, which is essentially a modified bed load transport model, to predict the slow evolution of an armor layer profile.

\section{TIME-AVERAGED PROBABILISTIC MODEL FOR PERMEABLE WET AND DRY ZONE}

A time-averaged probabilistic model is improved by developing a wet and dry model for permeable structures which is connected to the wet model developed by Kobayashi et al. (2007). The time-averaged cross-shore continuity and momentum equations for the nonlinear shallow-water waves is derived for the permeable wet and dry zone based on the assumption of the exponential probability distribution of water depth. These equations are coupled with the continuity and momentum equations for the flow inside the permeable layer. The model predicts the cross-shore variation of the mean and standard deviation of the water depth and velocity as well as the wet probability. The model is

\footnotetext{
${ }^{1}$ Center for Applied Coastal Research, University of Delaware, Newark, Delaware 19716, USA

${ }^{2}$ US Army Engineer Research and Development Center, 3909 Halls Ferry Road, Vicksburg, MS 39180-6199, USA
} 
compared with 52 experimental tests of wave overtopping on permeable structures (Kobayashi et al. 2010).

\subsection{Model Description}

The numerical model assumes that the incident waves are normal to the structure which is uniform in the longshore direction. Fig. 1 shows the flow above and inside a permeable slope. The origin of the cross-shore coordinate system is located at the offshore boundary with the positive on-shore directed xcoordinate. The vertical coordinate $z$ is taken to be positive upward where the datum is $z=0$.

The still water level ( $S W L$ ) above the datum denoted as $S$ in Fig. 1 is allowed to vary in time during a storm or an experiment. The upper and lower boundaries of the permeable stone layer are located at $z=z_{b}(x)$ and $z_{p}(x)$, respectively, where the lower boundary is assumed to be impermeable to simplify the analysis. The mean water level $(M W L)$ is located at $z=(S+\bar{\eta})$ where $\bar{\eta}$ is the wave setup above $S W L$. The other variables in Fig. 1 are explained when they are introduced.

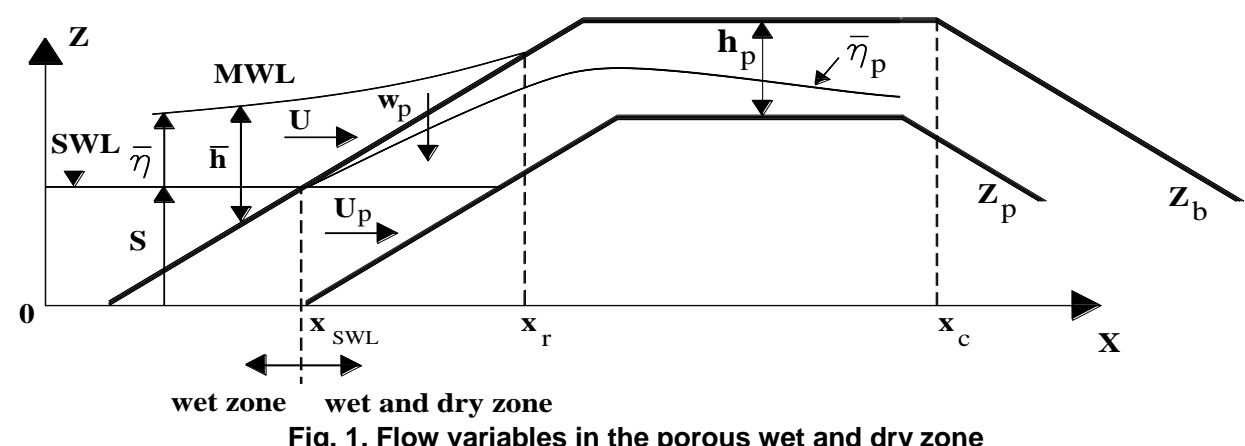

The time-averaged model for the wet permeable slope developed by Kobayashi et al. (2007) is modified using linear wave and current theory (e.g., Mei 1989) where wave overtopping induces onshore current. The time-averaged continuity, momentum, and wave action equations are used to predict the cross-shore variations of the mean $\bar{U}$ of the depth-averaged cross-shore velocity $U$, the mean $\bar{\eta}$ of the free surface elevation $\eta$ above $S W L$, and the free surface standard deviation $\sigma_{\eta}$. The overbar denotes time averaging. The root-mean-square $(R M S)$ wave height is defined as $H_{r m s}=\sqrt{8} \sigma_{\eta}$. Linear progressive wave theory is used locally to express the velocity standard deviation $\sigma_{U}$ in terms of $\sigma_{\eta}$. The probability distributions of $\eta$ and $U$ are assumed to be Gaussian. The equivalency of the time averaging and probabilistic averaging is assumed to express the time-averaged terms in the governing equations in terms of $\bar{\eta}, \sigma_{\eta}, \bar{U}$ and $\sigma_{U}$. The permeability effects are included in the same way as in Kobayashi et al. (2007).

The equations used for the present computation are presented in the reports by Kobayashi and Farhadzadeh (2008) and Farhadzadeh et al. (2009). The landward-marching computation using this model for the wet zone is continued as long as the computed $\bar{h}$ and $\sigma_{\eta}$ are larger than $0.1 \mathrm{~cm}$. The timeaveraged model for the wet zone cannot predict wave overtopping. Consequently, Kobayashi and de los Santos (2007) relied on empirical formulas for wave overtopping and seepage rates. Here, a separate model for the wet and dry zone is developed and connected with the model for the wet zone. This procedure is the same as that used by Kobayashi et al. (2010) for impermeable structures.

\subsection{Model Equations}

The time-averaged cross-shore continuity and momentum equations derived from the nonlinear shallow-water wave equations on the permeable slope (Wurjanto and Kobayashi 1993) are expressed as

$$
\begin{gathered}
\frac{d}{d x}(\overline{h U})=-\overline{w_{p}} \\
\frac{d}{d x}\left(\overline{h U^{2}}+\frac{g}{2} \overline{h^{2}}\right)=-g \bar{h} \frac{d z_{b}}{d x}-\frac{1}{2} f_{b} \overline{|U| U}-\overline{u_{b} w_{p}}
\end{gathered}
$$

The continuity and approximate momentum equations for the flow inside the permeable layer are expressed as

$$
\frac{d q_{p}}{d x}=\overline{w_{p}}
$$




$$
\left(\alpha_{p}+\beta_{1}\left|\overline{U_{p}}\right|\right) \overline{U_{p}}=-g \frac{d \bar{\eta}}{d x}
$$

with

$$
\alpha_{p}=1000\left(\frac{1-n_{p}}{n_{p}}\right)^{2} \frac{v}{D_{n 50}^{2}} ; \beta_{1}=\frac{5\left(1-n_{p}\right)}{D_{n 50} n_{p}^{3}}
$$

where $q_{p}=$ time-averaged horizontal volume flux in the permeable layer; $\overline{U_{p}}=$ time-averaged horizontal discharge velocity; $\alpha_{p}$ and $\beta_{1}=$ coefficients associated with the laminar and turbulent flow resistance, respectively; $n_{p}=$ porosity of the permeable layer; $D_{n 50}=$ nominal stone diameter; and $v=$ kinetic viscosity of the fluid. Eq. (5) is based on the formula developed by van Gent (1995) and calibrated by Kobayashi et al. (2007). The resistance component associated with the oscillatory flow is simply neglected in Eq. (4) which is solved analytically to obtain the discharge velocity $\overline{U_{p}}$ driven by the horizontal pressure gradient due to $\bar{\eta}=\left(\bar{h}+z_{b}-S\right)$ where $\bar{h}$ and $z_{b}$ vary with $x$. It is noted that Eq. (4) retains only the leading terms in the horizontal momentum equation given by Wurjanto and Kobayashi (1993).

Adding Eqs. (1) and (3) and integrating the resulting equation with respect to $x$, the vertically integrated continuity equation is obtained

$$
\overline{h U}+q_{p}=q_{o}
$$

where the wave overtopping rate $q_{o}$ is defined in this paper as the sum of the volume fluxes above and inside the permeable layer. The volume flux $q_{p}$ is estimated as

$$
q_{p}=P_{w} \overline{U_{p}}\left(\overline{\eta_{p}}-z_{p}\right)
$$

where $P_{w}=$ wet probability defined as the ratio between the wet and entire durations: $\overline{\eta_{p}}=$ average water level inside the permeable layer; and $z_{p}=$ elevation of the impermeable lower boundary. To estimate the volume flux $q_{p}$ in Eq. (7), $\overline{U_{p}}$ is obtained using Eq. (4). In addition, the mean water level inside the permeable layer $\overline{\eta_{p}}$ needs to be predicted. The elevation $\overline{\eta_{p}}$ and $z_{p}$ are relative to the datum $z=0$ in Fig. 1 and $\left(\overline{\eta_{p}}-z_{p}\right)$ is the thickness of water inside the permeable layer. The elevation $\overline{\eta_{p}}$ is estimated as

$$
\begin{aligned}
& \overline{\eta_{p}}=P_{w} z_{b}+\left(1-P_{w}\right) z_{p} \quad \text { for } \quad z_{p} \geq S \\
& \overline{\eta_{p}}=P_{w} z_{b}+\left(1-P_{w}\right) S \quad \text { for } \quad z_{p}<S
\end{aligned}
$$

The upper bound of $\overline{\eta_{p}}$ for $P_{w}=1$ is the upper boundary of the permeable layer located at $z=z_{b}$. The lower bound of $\overline{\eta_{p}}$ for $P_{w}=0$ is the higher elevation of the lower boundary $z_{p}$ of the permeable layer and the still water level $S$. The wet probability $P_{w}$ in Eq. (7) ensures that $q_{p}=0$ if $P_{w}=0$. Eqs. (7) - (9) based on physical reasoning may be crude but are used along with Eqs. (4) and (5) to estimate $q_{p}$ for the known $\bar{h}$ and $P_{w}$.

In order to account for both permeable layer thickness and wet probably, the last term in Eq. (2) is expressed as

with

$$
\overline{u_{b} w_{p}}=\alpha_{m} P_{w}(g \bar{h})^{0.5} w_{m} \quad ; \quad \alpha_{m}=2\left(\frac{z_{b}(x)-z_{p}(x)}{D_{n 50}}\right)^{0.3}
$$

$$
\left(\alpha_{p}+\beta_{1} w_{m}\right) w_{m}=g
$$

where $\alpha_{m}$ is an empirical parameter that includes the effect of the permeable layer thickness. The empirical parameter for $\alpha_{m}$ was based on wave overtopping data (Farhadzadeh et al. 2009). $w_{m}$ is the maximum downward seepage velocity due to the gravity force obtained analytically using Eq.(11). The seepage velocity $w_{p}$ is assumed to be of the order of $w_{m}$ or less. The horizontal velocity $u_{b}$ at $z=z_{b}$ is assumed to be of the order of $(g \bar{h})^{0.5}$. Eq. (10) assumes that the downward flux of the horizontal momentum during the wet duration is much larger than the upward momentum flux from the permeable layer. Therefore, the upward momentum flux is assumed to have no contribution to the momentum equation.

The cross-shore variation of the mean water depth $\bar{h}$ is obtained by solving the momentum equation (2) together with the continuity equation (6). Kobayashi et al. (1998) studied the probability 
distributions of free surface elevations on a beach. They found that the probability distribution function $f(h)$ in the lower swash zone can be presented in the form of an exponential function. This assumption simplifies the cross-shore model in the wet and dry zone. The exponential probability density function $f(h)$ is expressed as

$$
f(h)=\frac{P_{w}^{2}}{\bar{h}} \exp \left(-P_{w} \frac{h}{\bar{h}}\right) \text { for } h>0
$$

with

$$
P_{w}=\int_{0}^{\infty} f(h) d h \quad ; \quad \bar{h}=\int_{0}^{\infty} h f(h) d h
$$

The wet probability $P_{w}$ equals the probability of the instantaneous water depth $h>0$. As a result, the dry probability of $h=0$ is equal to $\left(1-P_{w}\right)$. The mean water depth for the wet duration is $\bar{h}$ but the mean depth for the entire duration is equal to $P_{w} \bar{h}$.

The free surface elevation $\eta$ above $S W L$ is given by $\eta=\left(h+z_{b}-S\right)$ where $z_{b}$ and $S$ are assumed to be invariant during the averaging. The standard deviations of $\eta$ and $h$ are the same and given by

$$
\frac{\sigma_{\eta}}{\bar{h}}=\left(\frac{2}{P_{w}}-2+P_{w}\right)^{0.5}
$$

which yields $\sigma_{\eta}=\bar{h}$ for $P_{w}=1$. This equality was supported by the depth measurement in the lower swash zone by Kobayashi et al. (1998) who assumed $P_{w}=1$ in Eq. (12).

The cross-shore velocity $U$ may be related to the depth $h$ in the wet and dry zone and expressed as

$$
U=\alpha \sqrt{g h}+U_{s}
$$

where $\alpha=$ positive constant; and $U_{s}=$ steady velocity which is allowed to vary with $x$. The steady velocity $U_{s}$ is included to account for offshore return flow on the seaward slope and crest and the downward velocity increase on the landward slope. Holland et al. (1991) measured the bore speed and flow depth on a barrier island using video techniques and obtained $\alpha \simeq 2$ where the celerity and fluid velocity of the bore are assumed to be approximately the same. As a result, use may be made of $\alpha \simeq$ 2 as a first approximation. Based on Eq. (15), the cross-shore velocity in the wet and dry zone increases as the water depth increases and approaches the steady velocity $U_{s}$ as the depth approaches zero. Using Eqs. (12) and (15), the mean $\bar{U}$ and standard deviation $\sigma_{\mathrm{U}}$ of the cross-shore velocity $U$ can be expressed as

$$
\begin{gathered}
\bar{U}=\frac{\sqrt{\pi}}{2} \alpha\left(P_{w} g \bar{h}\right)^{0.5}+P_{w} U_{s} \\
\sigma_{U}^{2}=\alpha^{2} g \bar{h}-2\left(\bar{U}-U_{s}\right)\left(\bar{U}-P_{w} U_{s}\right)+P_{w}\left(\bar{U}-U_{s}\right)^{2}
\end{gathered}
$$

Eqs. (14), (16) and (17) express $\sigma_{\eta}, \bar{U}$ and $\sigma_{U}$ in terms of $\bar{h}, P_{w}$ and $U_{s}$ which vary with $x$. Eq. (15) is substituted into Eqs. (2) and (6) which are averaged for the wet duration using Eq. (12). The continuity equation (6) yields

$$
\frac{3 \sqrt{\pi} \alpha}{4} \bar{h}\left(\frac{g \bar{h}}{P_{w}}\right)^{0.5}+U_{s} \bar{h}=q \quad ; \quad q=q_{o}-q_{p}
$$

where $q=$ volume flux above the permeable layer. After lengthy algebra, the momentum equation (2) is expressed as

$$
\frac{d}{d x}\left(B \frac{g \bar{h}^{2}}{P_{w}}+\frac{q^{2}}{\bar{h}}\right)=-g \bar{h} \frac{d z_{b}}{d x}-\frac{f_{b}}{2} \alpha^{2} g \bar{h} G_{b}(r)-\alpha_{m} P_{w}(g \bar{h})^{0.5} w_{m}
$$

with

$$
B=\left(2-\frac{9 \pi}{16}\right) \alpha^{2}+1 \quad ; \quad r=\frac{3 \sqrt{\pi}}{4} \frac{U_{s} \bar{h}}{q-U_{s} \bar{h}}
$$

where the parameter $B$ is related to the momentum flux term on the left hand side of Eq. (2). The function $G_{b}(r)$ in Eq. (19) is given by

$$
\begin{array}{lr}
G_{b}(r)=1+\sqrt{\pi} r+r^{2} & \text { for } r \geq 0 \\
G_{b}(r)=2 \exp \left(-r^{2}\right)-r^{2}-1+\sqrt{\pi} r[2 \operatorname{erf}(r)+1] & \text { for } r<0
\end{array}
$$


where $\operatorname{erf}$ is the error function. The function $G_{b}$ increases monotonically with the increase of $r$. The values of $G_{b}$ are equal to 0 and 1 for $r=-0.94$ and 0 , respectively. For $r<-1.5, G_{b}$ can be approximated as $G_{b} \simeq-\left(1+\sqrt{\pi} r+r^{2}\right)$.

Eqs. (18) and (19) are used to predict the cross-shore variation of $\bar{h}$ and $U_{s}$ for assumed $q_{o}$. It is necessary to estimate the wet probability $P_{w}$ empirically. To simplify the integration of Eq. (19), the following formula is adopted:

$$
P_{w}=\left[\left(1+A_{1}\right)\left(\frac{\bar{h}}{\bar{h}}\right)^{n}-A\left(\frac{\bar{h}}{\bar{h}}\right)^{3}\right]^{-1} ; A=\frac{q^{2}}{B g \bar{h}_{1}^{3}} ; A_{1}=\frac{q_{1}^{2}}{B g \bar{h}_{1}^{3}}
$$

where $\overline{h_{1}}$ and $q_{1}=$ mean water depth and volume flux, respectively, at the location of $x=x_{1}$ where $P_{w}=$ 1; $n=$ empirical parameter for $P_{w}$; and $A$ and $A_{l}=$ dimensionless variables related to $q$ and $q_{1}$, respectively. The transition from the wet $\left(P_{w}=1\right.$ always $)$ zone to the wet and dry $\left(P_{w}<1\right)$ zone may be taken at $x_{1}=x_{S W L}$ where $x_{S W L}$ is the cross-shore location of the still water shoreline of an emerged crest as shown in Fig. 1. Eq. (23) is assumed to be valid on the upward slope and horizontal crest in the region of $x_{1} \leq x \leq x_{c}$ where $x_{c}$ is the highest and most landward location of the structure as shown in Fig. 1. Eq (23) reduces to that used by Kobayashi et al. (2010) for an impermeable structure with $q=q_{1}$ $=q_{o}$.

Integration of Eq. (19) for $P_{w}$ given by Eq. (23) starting from $\bar{h}=\bar{h}_{1}$ at $x=x_{1}$ yields

$$
B_{n}\left(1+A_{1}\right) \bar{h}_{1}\left[\left(\frac{\bar{h}_{1}}{\bar{h}}\right)^{n-1}-1\right]=z_{b}(x)-z_{b}\left(x_{1}\right)+\int_{x_{1}}^{x}\left[\frac{f_{b}}{2} \alpha^{2} G_{b}+\alpha_{m} \frac{P_{w} w_{m}}{(g \bar{h})^{0.5}}\right] d x
$$

where $B_{n}=B(2-n) /(n-1)$; and $z_{b}(x)=$ bottom elevation at the cross-shore location $x$. The mean water depth $\bar{h}$ at given $x$ is computed by solving Eq. (24) iteratively. The empirical parameter $n$ is taken to be in the range of $1<n<2$ so that $B_{n}>0$. The formula for $n$ calibrated by Kobayashi et al. (2010) using 207 tests for wave overtopping of smooth impermeable structures is expressed as $n=1.01+0.98\left[\tanh \left(A_{o}\right)\right]^{0.3}$ where $1.01 \leq n \leq 1.99$ and $A_{o}=q_{o}^{2} /\left(B g \bar{h}_{1}^{3}\right)$.

On the downward slope in the region of $x>x_{c}$, the wet probability $P_{w}$ is assumed to be given by

$$
P_{w}^{-1}=P_{c}^{-1}+\frac{q_{c}^{2}-q^{2}}{B g \bar{h}^{3}}
$$

where $P_{c}$ and $q_{c}$ are the computed wet probability $P_{w}$ and volume flux $q$ at $x=x_{c}$. For the case where the landward slope is impermeable, $q=q_{c}=q_{o}$ and then $P_{w}$ is equal to $P_{c}$.

Substituting Eq. (25) into Eq. (19) and integrating the resulting equation from $x_{c}$ to $x$, the mean depth $\bar{h}(x)$ is expressed as

$$
\frac{\bar{h}}{\bar{h}_{c}}-1+\frac{P_{c} q_{c}^{2}}{4 g B \bar{h}_{c}^{3}}\left[\left(\frac{\bar{h}_{c}}{\bar{h}}\right)^{2}-1\right]=\frac{P_{c}}{2 B \bar{h}_{c}}\left\{z_{b}\left(x_{c}\right)-z_{b}(x)-\int_{x_{c}}^{x}\left[\frac{f_{b}}{2} \alpha^{2} G_{b}+\alpha_{m} \frac{P_{w} w_{m}}{(g \bar{h})^{0.5}}\right] d x\right\}
$$

where $\overline{h_{c}}$ is the computed mean depth at $x=x_{c}$.

The wave overtopping rate $q_{o}$ is predicted by imposing $U_{s}=0$ in Eq. (18) at the crest location $x_{c}$

$$
q_{o}=\frac{3 \sqrt{\pi} \alpha}{4} \bar{h}_{c}\left(\frac{g \bar{h}_{c}}{P_{c}}\right)^{0.5}+q_{p} \quad \text { at } x=x_{c}
$$

The wave overtopping probability $P_{o}$ may be related to the wet probability $P_{c}$ at $x=x_{c}$ where both $P_{o}$ and $P_{c}$ are in the range of $0.0-1.0$. The empirical relation of $P_{o}=\left[\tanh \left(5 P_{c}\right)\right]^{0.8}$ was fitted by Kobayashi et al. (2010) using 207 tests for wave overtopping of smooth impermeable structures.

In order to evaluate the numerical model for the permeable wet and dry zone, the computed results have been compared with 52 experimental tests of wave overtopping on permeable structures including 12 seepage tests, 10 overtopping and seepage tests (Kobayashi and de los Santos 2007) and 12 overtopping tests (Kobayashi and Raichle 1994). The comparison was also made with D' test series of 18 tests by van Gent (2002). The seaward slope of the structures was in the range of $1 / 5$ to $1 / 2$. The 
comparisons showed the model capability of predicting the wave hydrodynamics parameters within a factor of two (Kobayashi et al. 2010).

\section{ARMOR LAYER EVOLUTION MODEL}

The sediment transport model for the wet zone developed by Kobayashi et al. (2009) is modified to predict the movement of stone armor units on a coastal structure. The probability $P_{b}$ of stone movement under the Gaussian velocity $U$ in the wet zone is estimated assuming that the stone movement occurs when the absolute value of the instantaneous velocity $U$ exceeds the critical velocity $U_{c b}$ estimated as

$$
U_{c b}=\left[N_{c} g(s-1) D_{n 50}\right]^{0.5}
$$

where $S$ and $D_{n 50}=$ specific gravity and nominal diameter of the stone; and $N_{c}=$ empirical parameter. If the wave height $H_{c}$ corresponding to $U_{b c}$ is given by $H_{c}=U_{b c}^{2} / g$, Eq. (28) yields

$$
N_{c}=H_{c} /\left[(s-1) D_{n 50}\right]
$$

where $N_{c}$ may be regarded as the critical stability number for the stone which is of the order of unity (Kobayashi et al. 2003). Kobayashi et al. (2009) used the critical Shields parameter $\Psi_{c}=0.05$ for the initiation of sand movement. The two parameters are related by $N_{c}=2 \Psi_{c} / f_{b}$ and the equation of the probability $P_{b}$ given by Kobayashi et al. (2009) is applicable using $\Psi_{c}=0.5 f_{b} N_{c}$. Eq. (29) is adopted here and $N_{c}$ is calibrated as $N_{c}=0.7$ using the damage progression tests of a stone structure with $S=$ 2.66 and $D_{n 50}=3.64 \mathrm{~cm}$ conducted by Melby and Kobayashi (1998). The probability of stone suspension is estimated in the same way as in Kobayashi et al. (2009) where the stone fall velocity $w_{f}$ is estimated for a sphere (e.g., Jiménez and Madsen 2003) as

$$
w_{f}=1.8\left[g(s-1) D_{n 50}\right]^{0.5}
$$

For the stone with $S=2.66$ and $D_{n 50}=3.64 \mathrm{~cm}, w_{f}=1.4 \mathrm{~m} / \mathrm{s}$ and the computed probability of suspension of this stone is essentially zero. The stone armor units are assumed to move like bed load particles in the following.

The probability $P_{b}$ of stone movement in the wet and dry zone is obtained for the probability distribution of $U$ based on Eqs. (12) and (15). The probability $P_{b}$ of stone movement is assumed to be the same as the probability of $|U|>U_{c b}$ with $U_{c b}$ given by Eq. (28) and is estimated as

$$
\begin{array}{lr}
P_{b}=P_{w} & \text { for } U_{s}>U_{c b} \\
P_{b}=P_{w} \exp \left[-\frac{P_{w}\left(U_{c b}-U_{s}\right)^{2}}{\alpha^{2} g \bar{h}}\right] & \text { for }\left|U_{s}\right| \leq U_{c b} \\
P_{b}=P_{w}\left\{1-\exp \left[-\frac{P_{w}\left(U_{c b}+U_{s}\right)^{2}}{\alpha^{2} g \bar{h}}\right]+\exp \left[-\frac{P_{w}\left(U_{c b}-U_{s}\right)^{2}}{\alpha^{2} g \bar{h}}\right]\right\} & \text { for }-U_{s}>U_{c b}
\end{array}
$$

where the upper limit of $P_{b}$ is the wet probability $P_{w}$ because no stone movement occurs during the dry duration.

The time-averaged volumetric rate $q_{b}$ of stone transport is estimated using the formula for bed load in the wet zone proposed by Kobayashi et al. (2009)

with

$$
q_{b}=b P_{b} G_{s} B_{r} \sigma_{U}^{3} /[g(s-1)] \quad ; \quad B_{r}=\left(\frac{z_{b}-z_{p}}{D_{n 50}}\right)^{m} \leq 1
$$

$$
\begin{array}{lc}
G_{s}=\tan \varphi /\left(\tan \varphi+S_{b}\right) & \text { for }-\tan \varphi<S_{b}<0 \\
G_{s}=\left(\tan \varphi-2 S_{b}\right) /\left(\tan \varphi-S_{b}\right) & \text { for } 0<S_{b}<\tan \varphi
\end{array}
$$


where $b=$ bed load parameter; $G_{s}=$ function of the bottom slope $S_{b}=\partial z_{b} / \partial x ; B_{r}=$ reduction factor due to limited stone availability; $m=$ empirical parameter calibrated later; $\sigma_{U}=$ velocity standard deviation representing the wave action on the stone; and $\tan \varphi=$ limiting slope of the stone. The rate $q_{b}$ becomes negative (offshore) on the steep slope of $S_{b}>(\tan \varphi / 2)$ and $G_{s}<0$. Use is simply made of $b=0.002$ and $\tan \varphi=0.63$ adopted by Kobayashi et al. (2009). The reduction factor $B_{r}$ is added here to account for the thickness $\left(z_{b}-z_{p}\right)$ of the stone layer where $B_{r}=1$ if $\left(z_{b}-z_{p}\right)>D_{n 50}$ and $B_{r}=0$ in the zone of $z_{b}=z_{p}$ and no stone. The rate $q_{b}$ of stone transport in the wet and dry zone is also estimated using Eq. (34) where the parameter $b$ is chosen so that the values of $q_{b}$ computed for the two different zones are the same at the still water shoreline located at $x=x_{\mathrm{SWL}}$. The computed crossshore variations of $q_{b}$ in the two zones are averaged in the overlapping zone of $x_{\mathrm{SWL}} \leq x \leq x_{r}$ for the smooth transition between the two zones.

Finally, the temporal change of the bottom elevation $z_{b}$ is computed using the conservation equation of stone volume per unit width

$$
\left(1-n_{p}\right) \frac{\partial z_{b}}{\partial t}+\frac{\partial q_{b}}{\partial x}=0
$$

where $t=$ slow time for the profile change; and $n_{p}=$ stone porosity which is assumed to remain constant. Eq. (37) is solved numerically to obtain the bottom elevation $z_{b}$ at the next time level (Kobayashi et al. 2009). The condition of $\partial q_{b} / \partial x=0$ is imposed at the landward end of the computation domain. This computation procedure is repeated starting from the initial bottom profile until the end of a profile evolution test. The computation time is of the order of $10^{-3}$ of the test duration.

\section{COMPARISON WITH DAMAGE PROGRESSION DATA}

To evaluate the damage progression model performance, the comparison is made with the damage progression tests for a rubble mound structure by Melby and Kobayashi (1998). Their stone structure tests include three tests $\mathrm{A}^{\prime}, \mathrm{B}^{\prime}$ and $\mathrm{C}^{\prime}$ with an identical structure profile and stone but different water levels, wave conditions and durations. The tests were designed to examine the long-term progression of the armor layer damage of a stone structure.

\subsection{Experiment by Melby and Kobayashi}

The experiment was conducted in a flume of $61.1 \mathrm{~m}$ long, $1.52 \mathrm{~m}$ wide, and $2.0 \mathrm{~m}$ high. Fig. 2 shows the structure cross section. The beach slope was $1 / 20$. The height of the rubble mound structure was $30.5 \mathrm{~cm}$ above the toe of the seaward slope of $1 / 2$. The crest width was $11 \mathrm{~cm}$. The armor stone was placed in a traditional two-layer thickness. The armor stone was characterized by $D_{n 50}=3.64 \mathrm{~cm}$, $s=2.66$ and $n_{p}=0.4$ where the maximum seepage velocity is $w_{m}=8.7 \mathrm{~cm} / \mathrm{s}$ estimated using Eq. (11). The thickness of the armor layer was $7.3 \mathrm{~cm}$. The underlayer was $2.9-\mathrm{cm}$ thick and consisted of stone in the size range of $1.27-1.59 \mathrm{~cm}$. The size of the core stone ranged from 0.47 to $0.67 \mathrm{~cm}$.

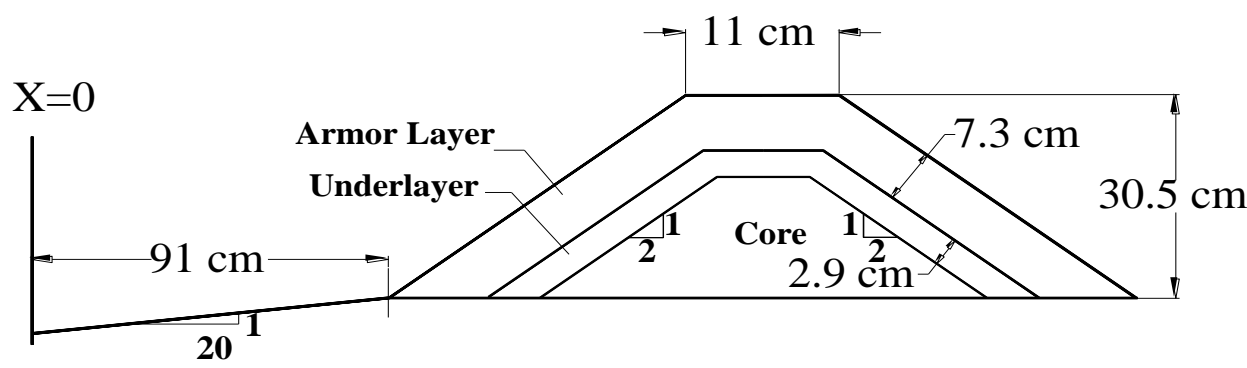

Fig. 2. Experimental setup for damage progression tests 
The still water depth below $z=0$ was $11.9 \mathrm{~cm}$ at the toe of the slope of $1 / 2$. Table 1 summarizes the still water level $S$ and wave conditions measured at the boundary $x=0$ in Fig. 1 . The time $t$ is the damage progression time starting from zero damage at $t=0$. The $R M S$ wave height $H_{r m s}$ was increased during constant $S$. The profiles were measured along 16 or 32 cross-shore lines every $0.5 \mathrm{~h}$. The average profiles are used here. The tests durations were $t_{e}=28.5,8.5$ and $9.0 \mathrm{~h}$ for tests A', B' and $\mathrm{C}^{\prime}$, respectively.

\begin{tabular}{|c|c|c|c|c|}
\hline Test & $t(\mathrm{~h})$ & $S(\mathrm{~cm})$ & $T_{p}(\mathrm{~s})$ & $H_{\text {rms }}(\mathrm{cm})$ \\
\hline \multirow{2}{*}{$A^{\prime}$} & $0.0-10.5$ & 0.0 & 2.48 & $6.9-10.0$ \\
\hline & $10.5-28.5$ & 3.9 & 2.59 & $7.4-11.2$ \\
\hline \multirow[b]{2}{*}{$B^{\prime}$} & $0.0-4.5$ & 0.0 & 2.48 & $6.9-10.0$ \\
\hline & $4.5-8.5$ & 3.9 & 2.59 & $9.6-11.2$ \\
\hline \multirow{2}{*}{$C^{\prime}$} & $0.0-5.0$ & 3.9 & 2.59 & $7.4-11.2$ \\
\hline & $5.0-9.0$ & 0.0 & 2.48 & $8.8-10.0$ \\
\hline
\end{tabular}

The damage progression model is calibrated because of the empirical parameters introduced in the model. In Eq. (34), the reduction factor $B_{r}$ is introduced with the empirical parameter $m$. The model is relatively insensitive to the parameter $m$ in the range of $0.5-2$. The computed profiles for the different values of $m$ were very similar. Therefore, $m$ is taken as $m=1$ for simplicity (Farhadzadeh et al. 2009).

As discussed earlier, the main empirical parameter in the damage progression model is the critical stability number $N_{c}$. To examine the sensitivity of the model to $N_{c}$, computation is made for the three tests using different $N_{c}=0.6$ and 0.7 .Eq. (28) states that the critical velocity $U_{c b}$ for the stone movement increases with the increase of $N_{c}$. Therefore, more damage is expected with $N_{c}=0.6$ than with $N_{c}=0.7$. The best agreement with the measured damage progression was achieved for $N_{c}=0.6$. However, the damage profiles for tests $\mathrm{A}^{\prime}, \mathrm{B}^{\prime}$ and $\mathrm{C}^{\prime}$ were predicted better for $N_{c}=0.7$ (Farhadzadeh et al. 2009). In the following $N_{c}=0.7$ is used.

\subsection{Comparison with Damage Tests}

The calibrated damage model is compared with the experiment by Melby and Kobayashi (1998). Computation was made by taking $z_{p}$ at the lower boundary of the underlayer as well as the armor layer in Fig. 2 to examine the effect of the permeable layer thickness. The difference of the computed results is found to be much smaller than the difference between the measured and computed results (Kobayashi et al. 2010). Therefore, the assumed impermeable boundary of $z=z_{p}$ is taken at the lower boundary of the armor layer. The measured and computed profiles $z_{b}(x)$ at the different time levels (see Table 1) are compared in Fig. 3 to 5 for tests A', B' and C', respectively. The numerical model underpredicts the eroded area as well as the deposited area below SWL. However, the deposited area is predicted better as the damage progresses in test A'.

The temporal variations of the measured and computed eroded areas $A_{e}$ using damage $S_{e}$ defined as $S_{e}=A_{e} / D_{n 50}^{2}$, computed overtopping rate $q_{o}$, input root-mean-square wave height $H_{r m s}$ and input still water level $S$, for test $\mathrm{A}^{\prime}, \mathrm{B}^{\prime}$ and $\mathrm{C}^{\prime}$ are plotted in Fig. 6 to 8. The initial upper and lower boundaries of the armor layer are shown in thin light solid and dash lines. The numerical model predicts the damage progression well partly because the critical stability number $N_{c}$ introduced in Eq. (28) is calibrated to be $N_{c}=0.7$ for these damage progression tests. The computed wave overtopping rates $q_{o}$ suggest that even though the wave overtopping rate is affected by the damage progression, the still water level and wave height at $x=0$ are more influential. However, the wave overtopping rate was not measured in this experiment. 


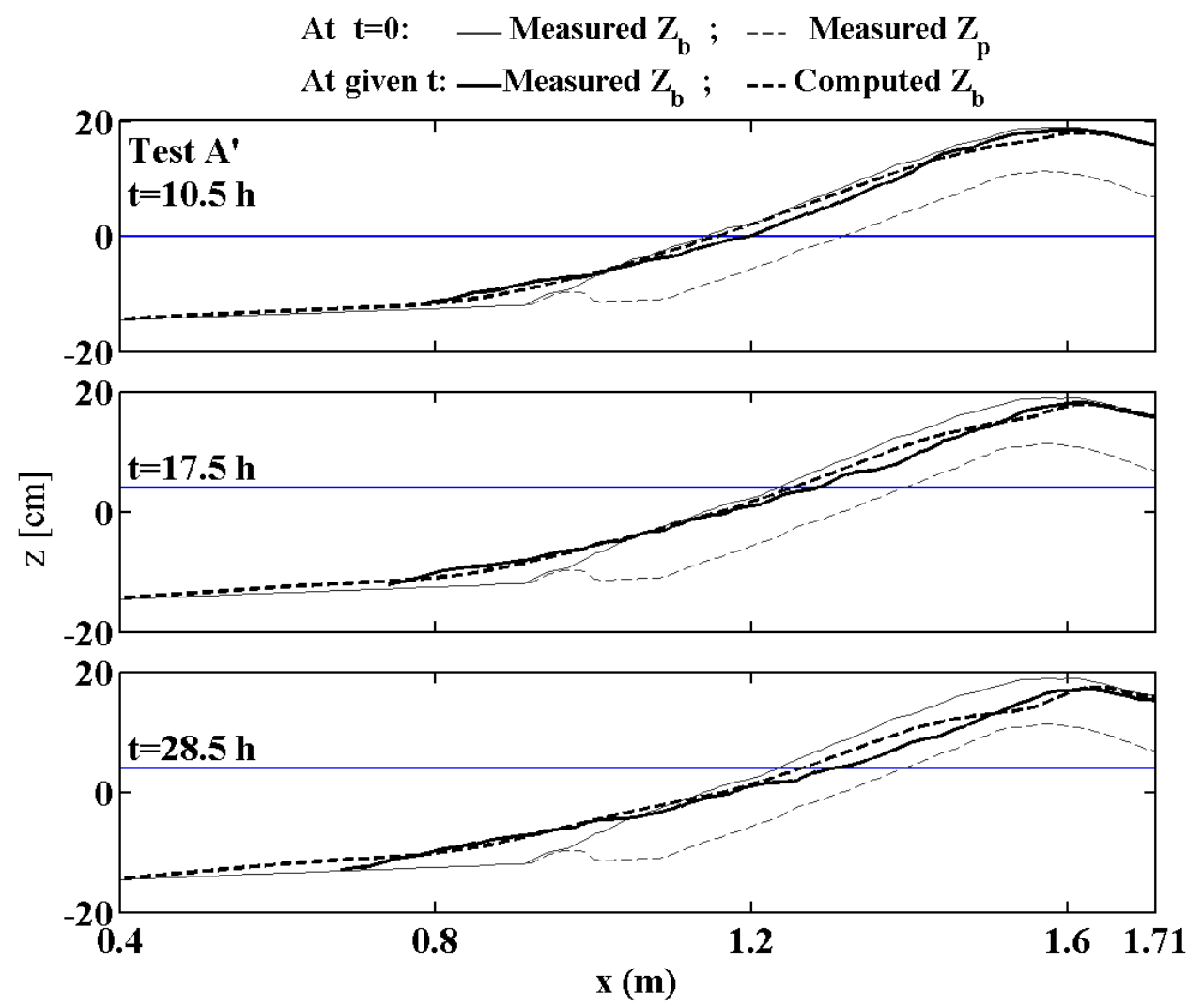

Fig. 3. Measured and computed damage profile for test $A^{\prime}$ at $t=10.5 h, 17.5 h$ and $28.5 h$

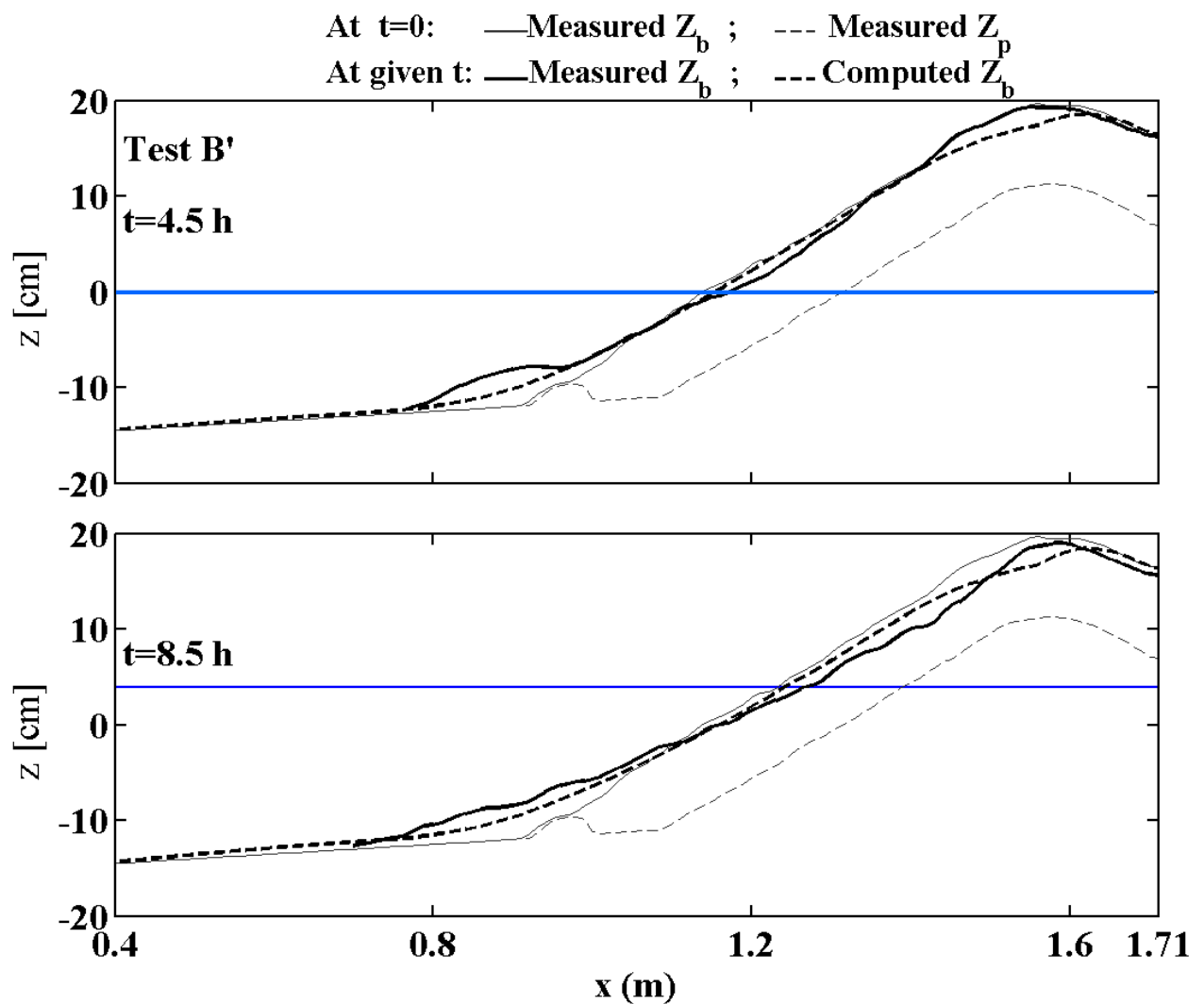

Fig. 4. Measured and computed damage profile for test $B^{\prime}$ at $t=4.5 \mathrm{~h}$ and $8.5 \mathrm{~h}$ 


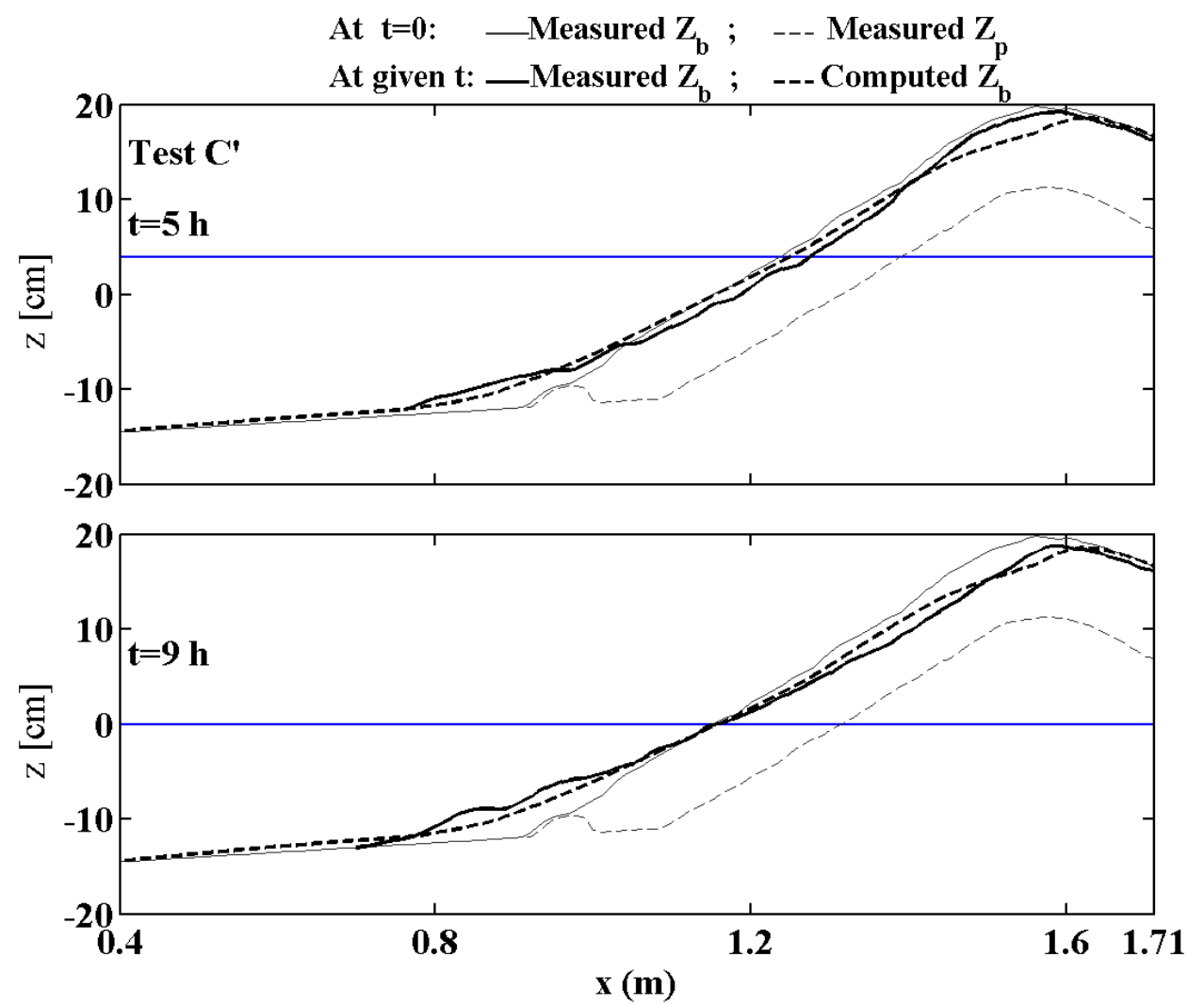

Fig. 5. Measured and computed damage profile for test $C^{\prime}$ at $t=5 \mathrm{~h}$ and $9 \mathrm{~h}$
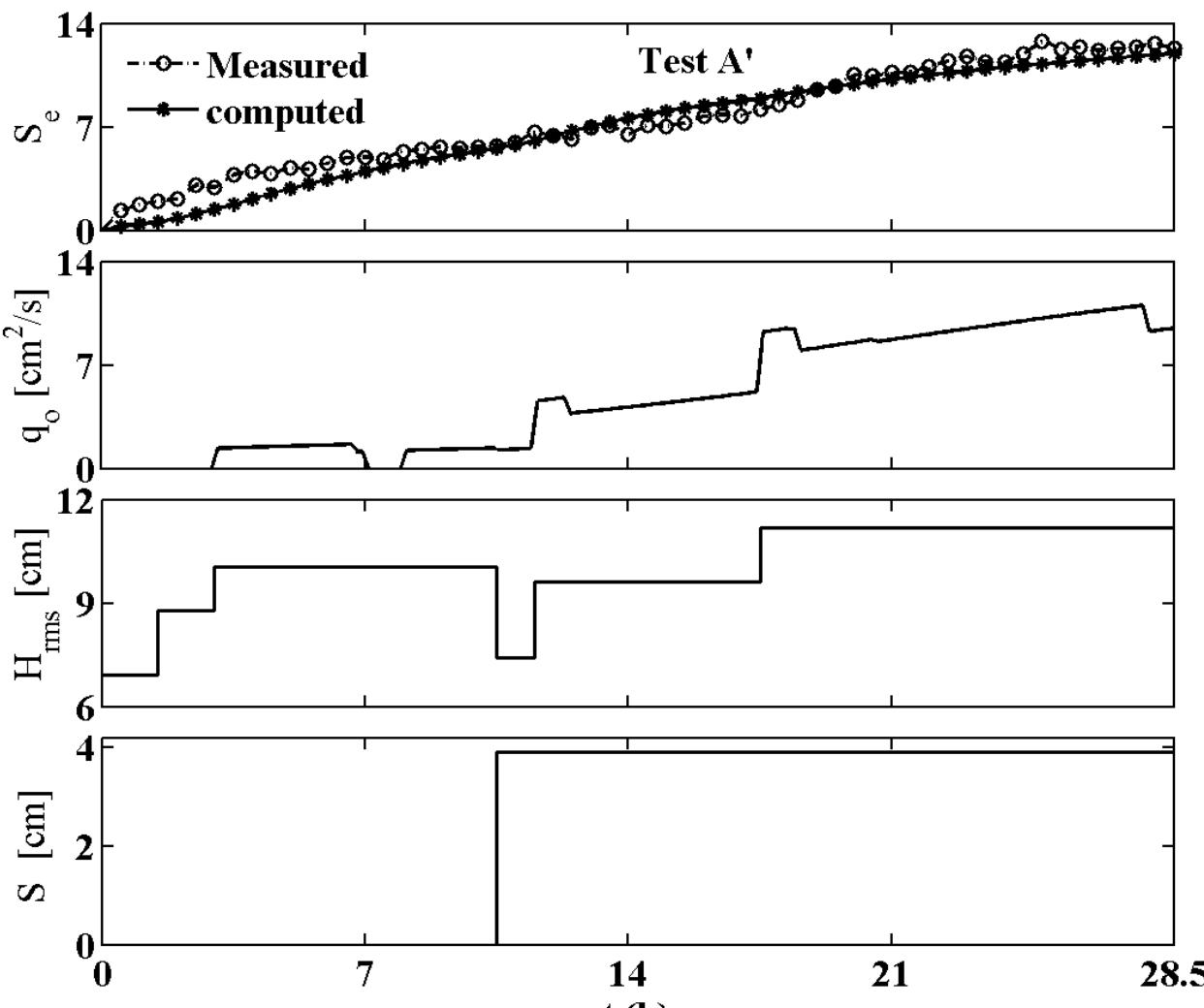

t (h)

Fig.6. Temporal variations of damage, overtopping rate, root-mean-square wave height and still water level for test $A^{\prime}$ 

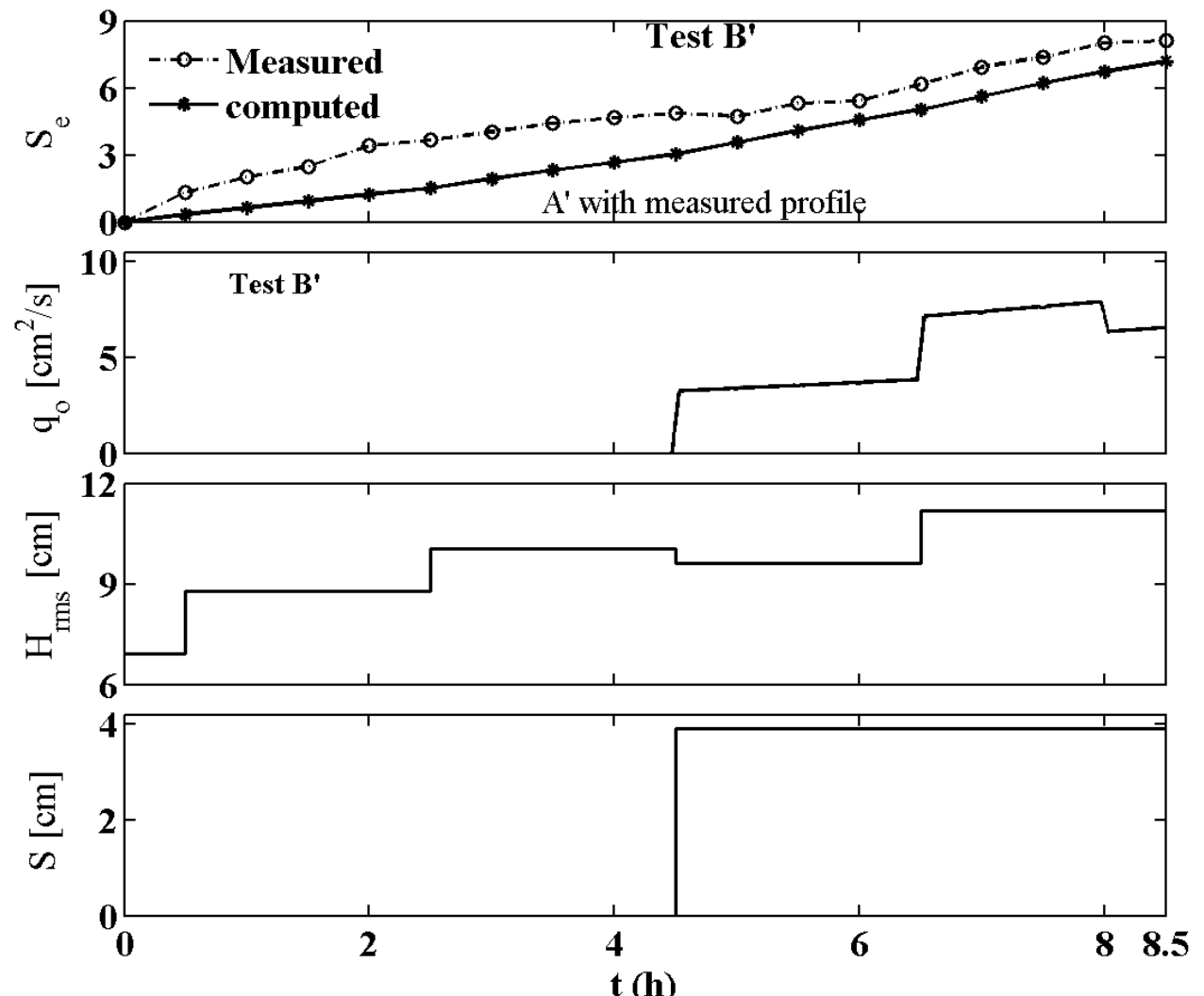

Fig.7. Temporal variations of damage, overtopping rate, root-mean-square wave height and still water level for test B'
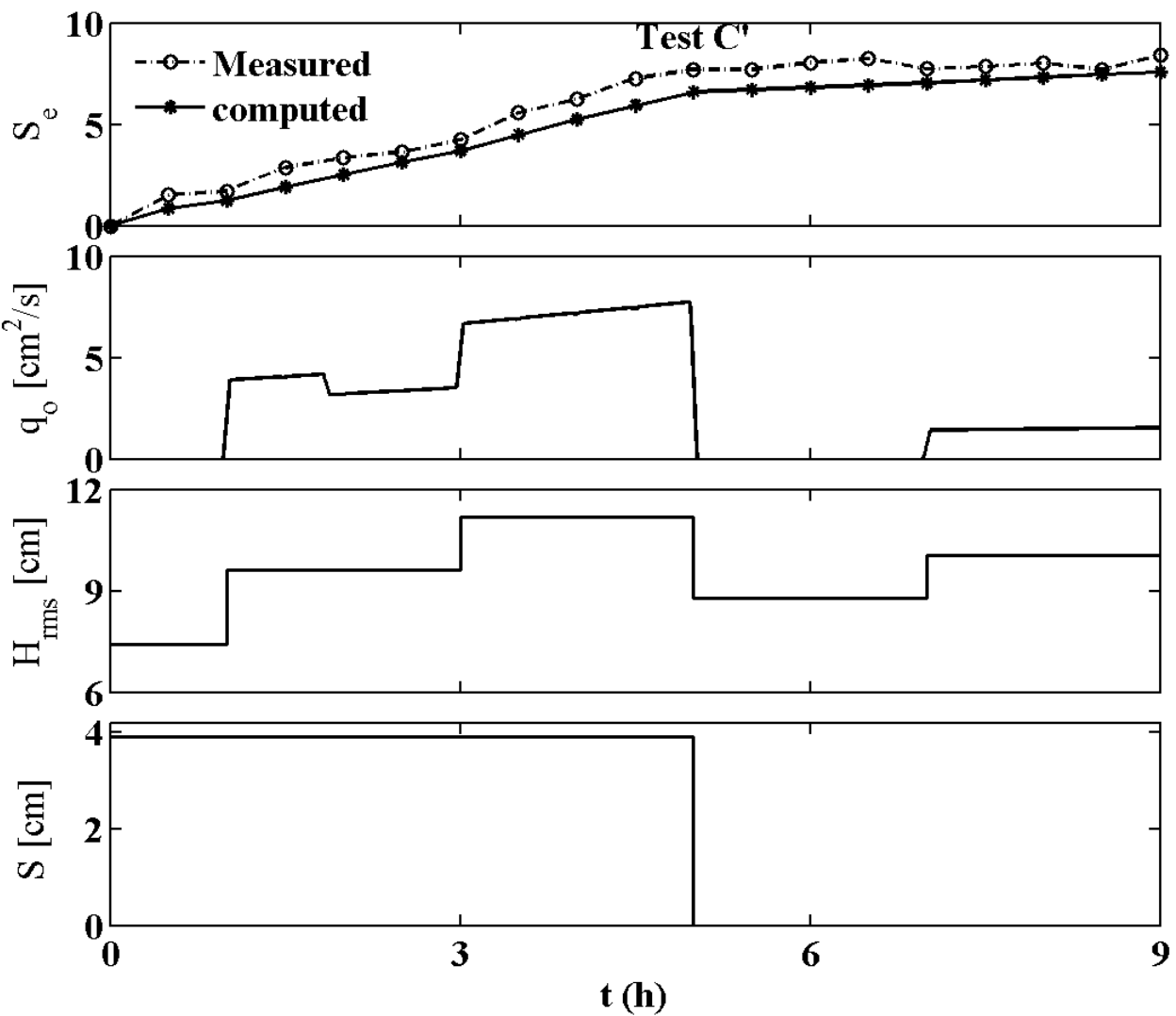

Fig.8. Temporal variations of damage, overtopping rate, root-mean-square wave height and still water level for test $\mathrm{C}^{\prime}$ 


\section{CONCLUSIONS}

A probabilistic hydrodynamic model for the wet and dry zone on a permeable structure is developed and connected with the model for the wet zone developed by Kobayashi et al. (2007) which is modified to account for onshore current induced by wave overtopping. The new model for the permeable wet and dry zone is based on the time-averaged continuity and momentum equations for nonlinear shallow-water waves coupled with the assumptions of the exponential probability distribution of the water depth $h$ given by Eq. (12) and the relation given by Eq. (15) between the horizontal velocity $U$ and $\mathrm{h}$. This model predicts the cross-shore variations of the mean and standard deviation of $h$ and $U$ and the wet probability $P_{w}$ within a factor of about 2. Nevertheless, data will be needed to evaluate the accuracy of Eqs. (12) and (15) directly.

Damage progression of a rubble mount structure is predicted by modifying the bed load formula proposed by Kobayashi et al. (2009) with input from the hydrodynamic model. The probability $P_{b}$ of stone movement is estimated using the critical velocity expressed by Eq. (28) which may be improved with the measurement of the individual stone movement and corresponding fluid velocity. The damage progression model is compared with three tests that lasted up to 28.5 hours. The model predicts the eroded and deposited areas of the damaged armor layer fairly well. The temporal variation of the eroded area is predicted well partly because Eq. (28) is calibrated for these three tests. The damage progression model will need to be verified using additional damage progression tests for different stone units and other armor units.

\section{ACKNOWLEDGMENTS}

This study was supported by the US Army Corps of Engineers, Coastal and Hydraulics Laboratory under contract Nos. W912HZ-10-P-0234 and W912BU-09-C-0023.

\section{REFERENCES}

Farhadzadeh, A., Kobayashi, N. and Melby, J.A.(2009). "Wave overtopping and damage progression on rubble mound structures". Research Report No. CACR-09-05, Center for Applied Coastal Research, Univ. of Delaware, Newark, Del.

Farhadzadeh, A., Kobayashi, N., Melby, J.A., and Ricottilli, C.(2007). "Experiments and numerical modeling of wave overtopping and overflow on dikes". Research Report No. CACR-07-02, Center for Applied Coastal Research, Univ. of Delaware, Newark, Del.

Holland, K.T., Holman, R.A., and Sallenger, A.H., Jr. (1991). "Estimation of overwash bore velocities using video techniques." Proc. Coastal Sediments'91, ASCE, Reston, Va., 489-497.

Jiménez, J.A., and Madsen, O.S. (2003). "A simple formula to estimate settling velocity of natural sediments.” J. Waterway, Port, Coastal, Ocean Eng., 129(2), 70-78.

Kobayashi, N., and de los Santos, F.J. (2007). "Irregular wave seepage and overtopping of permeable slopes." J. Waterway, Port, Coastal, Ocean Eng., 133(4), 245-254.

Kobayashi, N., and Otta, A.K. (1987). "Hydraulic stability analysis of armor units." J. Waterway, Port, Coastal, Ocean Eng., 113(2), 171-186.

Kobayashi, N., and Farhadzadeh, A. (2008). "Cross-shore numerical model CSHORE for waves, currents, sediment transport and beach profile evolution.” Research Rep. No. CACR-08-01, Center for Applied Coastal Research, Univ. of Delaware, Newark, Del.

Kobayashi, N., Pozueta, B., and Melby, J.A. (2003). "Performance of coastal structures against sequences of hurricanes." J. Waterway, Port, Coastal, Ocean Eng., 129(5), 219-228.

Kobayashi, N., Buck, M., Payo, A., and Johnson, B.D. (2009). "Berm and dune erosion during a storm." J. Waterway, Port, Coastal, Ocean Eng., 135(1), 1-10.

Kobayashi, N., Herrman, M.N., Johnson, B.D., and Orzech, M.D. (1998). "Probability distribution of surface elevation in surf and swash zones." J. Waterway, Port, Coastal, Ocean Eng., 124(3), 99107.

Kobayashi, N., Meigs, L.E., Ota, T., and Melby, J.A. (2007). "Irregular breaking wave transmission over submerged porous breakwaters.” J. Waterway, Port, Coastal, Ocean Eng., 133(2), 104-116.

Kobayashi, N., Farhadzadeh, A. and Melby, J.A. (2010). "Wave Overtopping and Damage Progression of Stone Armor Layer". J. Waterway, Port, Coastal, Ocean Eng., 136(5) (in press)

Kobayashi, N., Farhadzadeh, A., Melby, J.A., Johnson, B., and Gravens, M. (2010). "Wave overtopping of levees and overwash of dunes." J. Coastal Research (in press).

Mei, C.C. (1989). The Applied Dynamics of Ocean Surface Waves. World Scientific, Singapore.

Melby, J.A., and Kobayashi, N. (1998). "Progression and variability of damage on rubble mound breakwaters.” J. Waterway, Port, Coastal, Ocean Eng., 124(6), 286-294. 
van Gent, M.R.A. (1995). "Porous flow through rubble-mound material." J. Waterway, Port, Coastal, Ocean Eng., 121(3), 176-181.

van Gent, M.R.A. (2002). "Low-exceedance wave overtopping events: Measurements of velocities and the thickness of water-layers on the crest and inner slope of dikes." Delft Cluster Report DC 030202/H3802, Delft Hydraulics, Delft, The Netherlands.

Wurjanto, A., and Kobayashi, N. (1993). "Irregular wave reflection and runup on permeable slopes." J. Waterway, Port, Coastal, Ocean Eng., 119(5), 537-557. 